\title{
Post-settlement dispersal ability determines structure of marine benthic metacommunities
}

Martins, Gustavo M.; Matias, Miguel ; Moniz, Isadora; Ruis, Carlos ; Sanderson, Josephine ; Neto, Ana Isabel; Jenkins, Stuart

\section{Marine Ecology Progress Series}

DOI:

$10.3354 /$ meps 12108

Published: 01/04/2017

Peer reviewed version

Cyswllt i'r cyhoeddiad / Link to publication

Dyfyniad o'r fersiwn a gyhoeddwyd / Citation for published version (APA):

Martins, G. M., Matias, M., Moniz, I., Ruis, C., Sanderson, J., Neto, A. I., \& Jenkins, S. (2017). Post-settlement dispersal ability determines structure of marine benthic metacommunities. Marine Ecology Progress Series, 569, 15-23. https://doi.org/10.3354/meps12108

\footnotetext{
Hawliau Cyffredinol / General rights

Copyright and moral rights for the publications made accessible in the public portal are retained by the authors and/or other copyright owners and it is a condition of accessing publications that users recognise and abide by the legal requirements associated with these rights.

- Users may download and print one copy of any publication from the public portal for the purpose of private study or research.

- You may not further distribute the material or use it for any profit-making activity or commercial gain

- You may freely distribute the URL identifying the publication in the public portal?
}

Take down policy

If you believe that this document breaches copyright please contact us providing details, and we will remove access to the work immediately and investigate your claim. 
Running head: Dispersal determines metacommunity structure

${ }^{1}$ CE3C - Centre for Ecology, Evolution and Environmental Changes/Azorean Biodiversity Group, Universidade dos Açores, $9501-801$ Ponta 


\section{Abstract}

23 Changes in natural habitats and the community response to such changes have important impacts on the distribution of diversity. Theoretical

24 advances have highlighted the importance of including dispersal traits to predict responses to habitat loss but there is a lack of empirical

25 evidence. We investigated the effect of metacommunity size (by manipulating the number of habitat patches) and isolation (by manipulating

26 proximity to reefs) in structuring marine macrofaunal communities. The overall response of macrofauna to changes in habitat size and proximity

27 to reefs varied according to the species' ability to disperse after settlement. Whilst the richness of species with sessile adult stages responded to

28 proximity to reefs in which metacommunities were deployed, species with motile adult stages responded to metacommunity size. Results were

29 similar at both the patch- and metacommunity scales. A subsequent experiment showed that colonisation had an impact on the macrofaunal

30 responses to reef proximity, which persisted throughout the community assembly process. The inclusion of simple functional traits (i.e. post-

31 settlement dispersal) allows a better understanding of species responses to the spatial configuration of habitats at multiple ecological scales,

32 which may be key for predicting the consequences of habitat loss. 
34 Keywords: Biological traits, Community assembly, Experimental habitats, Habitat Size, Isolation, Scale. (e.g. MacArthur \& Wilson 1963, Rosenzweig 1995). The development of the field of spatial ecology has highlighted the importance of spatial

44 dynamics, connectivity and dispersal for the structure of populations and communities (MacArthur \& Wilson 1963, Rosenzweig 1995). This has led to a shift in focus from purely description of pattern, toward empirical and modelling approaches to understand the mechanistic basis of community change as a consequence of habitat modification (Holyoak 2000, Matias et al. 2010ab).

The effects of habitat area and isolation on population dynamics were formalized with the development of metapopulation (Hanski \& Gilpin 1991, Hanski 1994) and metacommunity (Leibold et al. 2004) theories, which resulted in a greater understanding of the role of 
coexistence mechanisms and dispersal and improved our ability to predict distributional patterns in spatially structured landscapes (Hanski

50 1999). Theory predicts that when habitat patches are destroyed, species may be able to persist if different populations are linked by dispersal

51 (Hanski \& Gilpin 1991, Hanski 1994). The ability to disperse and colonise new patches is therefore a key trait in determining patterns of species

52 diversity at different scales (Cadotte 2006).

It has been hypothesised that species' vulnerability to habitat loss and/or fragmentation, can be determined by species-specific life-

54 histories (Öckinger et al. 2010) or functional traits such as body size, dispersal ability, trophic level, diet breadth, among others (see Ewers \&

55 Didham 2006 for reviews). Previous studies measuring the effect of dispersal on metacommunity structure have often used indirect measures

56 (e.g. body-size), although recent studies have shown that dispersal mode or ability are better predictors of spatial patterns in macroinvertebrate

57 metacommunities (LeCraw et al. 2014). In order to make better predictions of the response of species to changes in habitats, further work is

58 required to determine how particular traits determine the ability of species to disperse and colonise habitat patches in interconnected

59 communities.

60 Despite these advances, there is still a disconnect between theoretical and empirical studies (see Logue et al. 2011). As suggested by

61 Logue et al. (2011), theoretical predictions should be tested empirically across a range of habitats and species to make a better link between

62 spatial dynamics, dispersal rate and mobility. One particular issue is that defining relevant spatial scales can be problematic (Srivastava 1999 ,

63 Munguia 2004). This issue has been raised by empirical work done both in marine (Munguia \& Miller 2008) and terrestrial (Miller \& Kneitel

64 2005) systems, where the possibility of very high long-distance dispersal for some species means that identifying regionally closed systems, 
assumed in most metacommunity theory, (e.g. Leibold et al. 2004) is challenging. It is likely that most metacommunities are not completely closed, at least at the scale that regional processes (such as dispersal and habitat heterogeneity) are thought to operate. In discussing metapopulations (the archetype for metacommunities), Hanski and Gilpin (1991) defined three scales: local, metapopulation and geographic; the geographic scale encompassing distances greater than those over which an individual moves over its lifetime. Recognising this caveat in the theoretical background of metacommunities, Cadotte and Fukami (2005) explicitly tested the effects of dispersal at two different scales: among local communities and among metacommunities. They found that dispersal at the two scales had distinct effects on diversity stressing the need to consider the effects of dispersal occurring at multiple scales rather than only at a regional scale. The above suggests that the metacommunity concept may be best applied in a less rigid manner than considered by most theory and that the effects of variability in dispersal (among species, rate or scale) must be further explored. to the structure and spatial configuration of habitat patches (Matias et al. 2007), including responses to changes in structural complexity (Kelaher 2003), habitat area and heterogeneity (Matias et al. 2010b), isolation (Virnsten \& Curran 1986) and environmental context (Matias 2013). We investigated the effects of metacommunity size on benthic assemblages colonising artificial turfs (i.e. patches) by manipulating the number of patches within groups of patches (analogous to metacommunity size sensu Leibold et al. 2004) and proximity to reefs within which 
metacommunities and that proximity to reefs would affect the numbers and identity of species present. We further predicted that the response of species to metacommunity size and proximity to reefs would depend on the post-settlement ability of species to disperse (e.g. whether species were motile or sessile after initial larval colonisation). While many of the benthic invertebrate species colonising artificial turfs have a planktonic larval phase and therefore the possibility of very high long-distance dispersal over regional scales, we focused on the implications of dispersal following settlement and specifically the difference between species which are motile or sessile as adults. Sessile species are not able, or unlikely capable, of further dispersal, whilst motile species are able to redistribute themselves at local scales. As such, we predicted that the numbers of species with sessile adult stages would remain relatively constant among habitats differing in size (provided that the sampled areas is

88 kept constant) as a simple response to habitat area, whilst species with motile adult stages, which have the ability to redistribute themselves after colonisation, would show variable patterns of distribution among habitats differing in size. Moreover, a greater number of sessile individuals, and hence species, would be expected to be found in habitats close to reefs (greater larval pressure close to reefs owing to the fact that it was the main source of larvae; mass effects), while motile species, whilst also influenced by the larval pressure during the colonization stage, again, would potentially have the ability to redistribute themselves after colonization. The latter, perhaps, may even be able to continuously exchange individuals between the reef and the nearby habitat patches. 
disperse (move) among habitat patches after settlement. That is, the process of patch colonization would be of greater importance in determining longer-term patterns of species distribution for sessile species compared to motile species. The latter was tested using a complementary experiment investigating the role of species' colonisation (early stages of community assembly) in determining the results observed over the longer-term (2-month period; the above experiment). We predicted that if early stages of species colonisation played an important role in determining community structure relative to post-colonisation processes (i.e. biotic interactions, dispersal), the response of species to distance from the reef during the very early stages of community assembly (3 days) would be similar to patterns observed during the 2-month experiment. In contrast, if post-colonisation processes were relatively more important for community structure, patterns established during early stages of species colonisation would be modified and results from both experiments would differ.

\section{MATERIALS AND METHODS}

\section{Study locations}

We chose two different locations about 500 m apart at São Roque (São Miguel, Azores: Latitude 3744'34' N, Longitude 25³8'31'’W). At each of the two locations, the rocky reef, composed of natural basaltic rocks, extends subtidally from the intertidal zone for 50 - $100 \mathrm{~m}$ offshore and is then replaced by sandy-bottom substrates. The transition zone between the reef and sand occurs at approximately $10-14 \mathrm{~m}$ depth at each of the two locations. Rocky reefs in the area support a rich flora dominated by turf-forming species (e.g. Corallina spp.) sustaining a diverse assemblage of macrofauna numerically dominated by gastropods ( 25\%) and amphipods ( 15\%) (Martins et al. 2016). The sandy- 
114 filicornis and the bivalve Ervilia castanea (Martins et al. 2013). All the experiments described below were replicated in each of these locations.

\section{Experiment 1: Metacommunity size and proximity to reef}

Patches of $50 \mathrm{~cm}^{2}$ of artificial turfs (40 mm long and sparse synthetic grass supplied by Maxmat, Ponta Delgada) were attached to the end of $50 \mathrm{~cm}$ metal rods (one patch per rod) that were driven into the sand leaving the artificial turfs at about $10 \mathrm{~cm}$ from the sea-bottom (see Fig. S1 in the supplement). Metacommunities of different sizes were created by deploying groups of either 3 or 6 patches. Within each metacommunity, patches were deployed about $10 \mathrm{~cm}$ from each other. We varied the proximity to the reef within which metacommunties were embedded by deploying patches at two different distances from the reef: close $(<2 \mathrm{~m})$ and away $(25 \mathrm{~m})$. Based on previous studies, macrofaunal assemblages adjacent to reefs are considerably different from those > $15 \mathrm{~m}$ away (Virnstein \& Curran 1986, Martins et al. 2013). Sandy habitats are locally dominated by polychaetes (Martins et al. 2013), which were mostly absent from our experimental patches. Only a small fraction $(\sim 7 \%)$ of species was found both in experimental patches and the adjacent sandy bottom, suggesting that assemblages colonising experimental patches originated mostly from the nearby algal-dominated reefs or directly from the water column. Overall, our approach of using patches of turf surrounded by an inhospitable habitat is similar to that used by Munguia \& Miller (2008) who used individual pen shells, as 'islands' of hard substrate habitat within seagrass beds grouped in metacommunities. 
In each of the two locations, three replicate metacommunities were deployed corresponding to each combination of metacommunity size and proximity to the reef (totalling 12 metacommunities and 54 individual patches per location, see Fig. S2 in the supplement). Experimental patches were deployed in early June 2012 and retrieved approximately 2 months after. This 2-month period is consistent with previous studies using these experimental habitat patches (e.g Kelaher 2002, Matias et al. 2007, 2010b). Moreover, preliminary observations conducted in the same locations as those in our experiment showed that numbers of species tended to stabilize after 2 weeks of patch deployment (see Fig. S3 in the supplement), which may indicate post-colonisation processes affecting the accumulation of species. From these considerations, the 2-month period was considered appropriate to allow the initial establishment of assemblages and to encapsulate post-settlement processes affecting assemblage structure (e.g. inter-patch dispersal by motile species). Upon collection, 3 individual patches from each replicate metacommunity were carefully removed from the rods and enclosed in plastic zip-closed bags while still underwater. Note that the number of patches sampled was always the same (3) for both the small and large metacommunity treatments so that the sampled area was consistent and is not a confounding factor. In the laboratory, samples were sieved ( $<2$ hours from collection) using a $0.5 \mathrm{~mm}$ sieve. The material retained was stored in alcohol in labelled plastic jars until further inspection.

\section{Experiment 2: Short-term colonisation}

An additional experiment was established to allow assessment of short-term colonisation patterns. In each of the two locations described above, 5 replicate habitat patches were deployed $(\sim 5 \mathrm{~m}$ apart $)$ both close $(<2 \mathrm{~m})$ and away $(25 \mathrm{~m})$ from the reef. Unlike in Experiment 1 , habitat 
patches were not grouped in metacommunities. Habitat patches were sampled (as described above) after a period of colonisation of only 3 days.

145 Because recruitment can show significant variability at small temporal scales this experiment was repeated three times between June-August

1462012. as adults into either motile or sessile as in Munguia (2004). Sessile species were species with sessile (permanently attached) adult stages (e.g. spirobid polychaetes, bryozoans), plus species that generally have little active locomotion as adults (e.g. bivalves). The latter are species that are unlikely to migrate among habitat patches after settlement. Motile species were those with an active means of locomotion (e.g. swimming, crawling) in the adult stage and that are therefore expected to be able to move freely among patches (e.g. amphipods, gastropods). Although initially we suspected that there could be a difference between crawlers and swimmers, preliminary analyses showed their response was similar and these were thus lumped together as a single group. One assumption made in this distinction between sessile and motile species was that sessile species once arriving (as larvae) and recruiting to a single habitat patch are no longer able or likely to disperse to the surrounding patches. among patches during their entire life-cycle. 


\section{Data analysis}

We conducted a permutational ANOVA (PERMANOVA based on Euclidean distances, Anderson 2001) to test for differences in the numbers of species using a 3-way fully factorial design: Size (fixed; small [3 patches] and large [6 patches]); Proximity to reef (fixed; close and away) and Location (random).

Multivariate analyses were used to examine the effects of size and proximity to the reef on the structure of macrofaunal assemblages. Analyses were run using permutational ANOVA as described above. These were run on two different similarity matrices: Bray-Curtis on untransformed data and Jaccard. Both indices explore differences in species composition. However, when calculated on untransformed data, Bray-Curtis gives more weight to changes in species abundances, whereas Jaccard does not take into account the species relative abundances and is based on changes in species identities alone. The combined use of these two measures of similarity allow assessment of the importance of changes in species abundances relative to changes in composition (e.g. Anderson 2005). Similarity of percentages (SIMPER) was used to identify the taxa contributing to differences within significant terms.

For all the above, analyses were run at two scales: patch- and metacommunity-scales. At the patch-scale, numbers of species were averaged from the three patches within each replicate metacommunity. At the metacommunity-scale, numbers of species was the total number of species found in each metacommunity (combining the 3 sampled patches per metacommunity).

The short-term colonisation experiment was analysed using permutational ANOVA with: Time (random; three random dates chosen between June-August 2013); Proximity to reef (fixed; close and away) and Location with two levels (random). 


\section{RESULTS}

\section{Experiment 1: Metacommunity size and proximity to reef}

A total of 145 taxa were identified from 57,558 individuals of which 123 were classified as motile and 22 as sessile (see Table S1 in supplement). Amphipods (65\% of total number individuals), motile polychaetes (5\%) and gastropods (4\%) were the dominant motile taxa. Bivalves (8\%), bryozoans (3\%) and sessile polychaetes (2\%) were the dominant sessile taxa. Most sessile (73\%) and motile (82\%) species were found both close and away from the reef. Species absent from the patches far from the reef were all rare or uncommon (c.a. 6 individuals per patch) in patches close to reef, whereas $<2 \%$ of species were exclusive to the areas away from the reef.

For the whole assemblage (both sessile and motile), the numbers of species varied depending on the scale (metacommunity- versus patch-scale) at which richness was measured. Macrofaunal richness responded significantly to proximity to the reef only at the metacommunityscale $\left(F_{1,19}=5.06, \mathrm{P}=0.036\right.$; Fig. 1a, see Table $\mathrm{S} 2$ in the supplement), with greater numbers of species colonising close to the reef (mean richness \pm SE, close to reef: $68.8 \pm 3.2$, far from reef: $60.4 \pm 2.0$ ). When considering the response of richness to metacommunity size, the number of species tended to be greater in large metacommunities both at the patch- (large: $47.8 \pm 1.8$, small: $42.0 \pm 2.3 ; F_{1,19}=3.77, \mathrm{P}=0.064$ ) and metacommunity-scale (large: $68.0 \pm 2.7$, small: $61.3 \pm 2.9 ; F_{1,19}=3.26, \mathrm{P}=0.09$ ) (Fig. 1b). 
When we analysed the data according to the dispersal traits, we found that there were significantly greater numbers of sessile species 192 closer to the reef at both the patch- $\left(27 \%\right.$ more species; $\left.F_{1,19}=8.73, \mathrm{P}=0.006\right)$ and metacommunity- $\left(28 \%\right.$ more species; $F_{1,19}=11.88, \mathrm{P}=$ 1930.003 ) scales (Fig. 1c,d). For motile species, proximity to the reef had no significant effect at the patch-scale $\left(F_{1,19}=0.91, \mathrm{P}=0.328\right)$. At the 194 metacommunity-scale, the number of species tended to greater $(11 \%)$ in patches close to reef $\left(F_{1,19}=3.42, \mathrm{P}=0.08\right)$.

Size had no effect on the numbers of sessile species at both the patch- $\left(F_{1,19}=1.08, \mathrm{P}=0.328\right)$ and metacommunity-scale $\left(F_{1,19}=0.92, \mathrm{P}\right.$ $=0.334$, Fig. $1 \mathrm{c}, \mathrm{d})$. Numbers of motile species were generally greater in larger habitats at both the patch-scale (large: $38.6 \pm 1.3$, small: $33.6 \pm$ $1.8 ; F_{1,19}=4.59, \mathrm{P}=0.048$ ) and metacommunity-scale (large: $54 \pm 2.0$, small: $\left.49.0 \pm 2.2 ; F_{1,19}=3.42, \mathrm{P}=0.084\right)($ Fig. $1 \mathrm{e}, \mathrm{f})$.

For the whole assemblage, the output of multivariate analyses was generally similar at the two scales (patch- and metacommunityscales). A significant interaction was found between metacommunity size and location (as well as between proximity to the reef and location) for both the Bray-Curtis and Jaccard similarity indices (see Table S3 in the supplement). Post hoc comparisons of these interaction terms showed consistent effect of both metacommunity size and proximity to reef (i.e. effects were seen at both locations) (Table 1).

When analysing data according to dispersal traits, we found that sessile assemblages did not respond to metacommunity size, but generally differed or tended to differ according to proximity to the reef (Jaccard, $\mathrm{P}<0.01$; Bray-Curtis, $\mathrm{P}=0.07$ ) (Table 1). SIMPER analysis (see Table S4 in the supplement) revealed that most sessile taxa occurred more often in habitats close to the reefs. Motile assemblages responded significantly to size and proximity to the reef (Table 1). The latter was, however, only significant when considering species abundances (Bray- 
average more abundant in large metacommunities. When considering the effect of proximity to the reef, most taxa were generally more abundant in metacommunities far from the reef.

\section{Experiment 2: Short-term colonisation}

A total of 103 taxa ( 89 motile and 14 sessile) were identified from 4,289 individuals. Motile assemblages were dominated by amphipods (58\%), gastropods (18\%) and decapods (4\%). Sessile assemblages were dominated by bryozoans (6\%) and bivalves (5\%). Most motile (71\%) and a large number of the sessile (54\%) species were found both far and away from reef.

For the whole assemblage (sessile and motile included) there was no effect of proximity to reef on numbers of species $\left(F_{1,2}=0.93, \mathrm{P}=\right.$ 0.377). When we considered dispersal traits, however, we found significantly $\left(F_{1,53}=4.30, \mathrm{P}=0.039\right)$ greater numbers of sessile species in patches close to the reef $(1.9 \pm 0.2)$ compared to patches away from the reef $(1.4 \pm 0.2)$. In contrast, the numbers of motile species did not vary with proximity to the reef $\left(F_{1,53}=0.84, \mathrm{P}=0.396\right)$ (see Fig. S4 and Table S5 in the supplement). Multivariate analysis showed that, proximity to the reef generally did not determine the structure of whole assemblages (Bray-Curtis: $\left.F_{1,53}=191, \mathrm{P}=0.126\right)$ although it appeared to have some effect on species identities (Jaccard: $\left.F_{1,53}=1.46 \mathrm{P}=0.083\right)$. When analysing data according to the dispersal traits, again there were significant differences in the structure of assemblages of sessile species with proximity to reef (Bray-Curtis: $F_{1,53}=4.09, \mathrm{P}=0.003$; Jaccard: $F_{1,53}=2.48, \mathrm{P}=0.046$ )(see table $\mathrm{S} 6$ in the supplement for ANOVAs). SIMPER analyses (see Table S7 in the supplement) showed that 5 out of the 8 sessile taxa accounting for $90 \%$ of the differences between habitat patches deployed at 
different distances from the reef were more frequent (found in a greater number of patches) in patches close to the reefs. In contrast to sessile assemblages, proximity to reefs had no significant effect in the assemblage structure of motile species (Bray-Curtis: Location $\mathrm{x}$ Time $\mathrm{x}$

Proximity to reef $F_{2,51}=1.34, \mathrm{P}=1.39 ;$ Proximity to reef $F_{1,2}=2.04, \mathrm{P}=0.167 ;$ Jaccard: $F_{1,53}=2.44, \mathrm{P}=0.110$ ).

\section{DISCUSSION}

Our study illustrates that, as expected, macrofaunal assemblages as a whole responded to differences in habitat configuration (metacommunity size and proximity to reef). More importantly, however, we found that the overall response of macrofauna varied according to species post-settlement dispersal abilities. For instance, results showed that assemblages of sessile and sedentary invertebrates were $c a$. $30 \%$ more diverse, and significantly so, in metacommunities deployed close to reefs, whereas motile invertebrates displayed no such pattern. Also post-settlement dispersal ability determined responses to metacommunity size: motile assemblages were more diverse (at both the patch- and metacommunity-scales) in larger metacommunities, while sessile assemblages did not respond to metacommunity size.

Making the distinction between species that are able to actively disperse as adults and species that are not proved useful in contributing to a greater understanding of the responses observed to variation in habitat configuration and may provide insights about the underlying mechanisms. For instance, a greater number of species in larger habitats probably indicates that a greater number of individual patches sample more of the species pool and that species once arriving to a single patch can, afterwards, disperse to other patches within a metacommunity. Thus on average (and not only at the metacommunity-scale), all patches within a metacommunity have more species. Post-settlement species 
dispersal among patches within metacommunities is, however, less likely in the case of sessile species and in accordance, there were no effects of size (at both the patch- and metacommunity-scales). The distinct response of sessile and motile taxa to changes in metacommunity size

241 highlights the importance of recognizing post-settlement dispersal among habitat patches in mediating the response of species to habitat loss.

242 Such considerations may prove particularly important, for instance, when considering the effects of variations in the spatial configuration of networks of marine protected areas on particularly important species (Shanks et al. 2003). In this regard, it would be important to investigate if

244 the results from our small-scale experiment can be scaled-up to larger spatial scales (i.e. reefs, coasts, islands). It should be noted, however, that processes affecting the distribution of larval recruitment may be relatively more important at explaining such larger-scale distributions (among MPAs) than the post-settlement ability of species to disperse among habitat patches (addressed in this study), which likely is more important at smaller spatial scales, although this may still be important in distinguish some species (e.g. cryptic reef fish vs benthonic fish). in proximity to reef (or source of colonists). Our prediction was that distance to a nearby reef plays an important role in structuring communities (e.g. Chase \& Ryberg 2004) with habitats further away from the reef supporting lower numbers of species. In accordance, assemblages of invertebrates with sessile adult stages were significantly influenced by the proximity to the reef with habitat patches deployed away from the reef supporting less diverse assemblages. Assemblages of invertebrates with motile adult stages, however, did not respond as predicted (and in fact showed greater abundances in habitats away from the reef). Here it seems that distance from a source of colonists was not the driver of community composition. Given the perceived and documented importance of habitat isolation for many organisms, including species with high 
levels of motility (reviewed by Cadotte 2006), it may be tentatively suggested that larval dispersal ability of the motile invertebrates during the colonisation stage was larger than the level of 'isolation' of patches deployed away from the reefs and that for some reason (e.g. higher rates of predation by reef fish, 'oasis' effect), the abundance of individuals is reduced close to the reef. It is interesting to note that this pattern of greater abundance of individuals recorded in patches further away from reefs was also shown by Virnstein and Curran (1986) for some amphipods.

While results were generally similar regardless of scale (patch- or metacommunty-scale), there were a few exceptions, most notably, the fact that when considering the assemblage as a whole, significant effects of proximity to reefs were found only at the metacommunity-scale. A possible explanation for this result might be attributed to the fact that probabilities of sampling rare species depend on the scale at which one measures species diversity (i.e. patch vs. metacommunity). It has been shown that differences between different habitat types might be driven simply by the presence or absence of rare species, with common species being present across all habitat types (Matias et al. 2010a). In our study, rare species often colonized a single patch within the metacommunity and, thus, their contribution to species diversity is reduced when diversity is measured at patch-scale (i.e. numbers of species were averaged from the three patches within each metacommunity). In contrast, metacommunities were colonised by multiple rare species (i.e. the sum of rare species in each of the three patches) that all contribute to species diversity at the metacommunity-scale. For this reason, the contribution of rare species is greater at the metacommunity-scale when compared to the patch-scale, providing a better "sample" of benthic organisms, since there were clearly fewer rare species away from the reef. These results show that the scale at which we measured diversity is inevitably linked to the degree to which the same measure of diversity is able to capture the effects of isolation. 

experiment investigating the short-term effects of habitat proximity to the reef on early patterns of species colonisation showed that patterns were consistent with those observed during the main experiment (no effect of proximity to reef on species with motile adult stages, greater richness of species with sessile adult stages close to the reef). Such consistent responses found between the two experiments imply a rather influential role of larval dispersal or colonisation over post-colonisation processes for community assembly in terms of patch isolation (proximity to reef). Note that the overall numbers of species colonising the individual patches in this short-term experiment ( 3 days) was relatively small for species with sessile adult stages (see Fig. S4b). The small number of sessile species colonising habitat patches may affect our ability to extrapolate these results to a wider assemblage of sessile species (as found in the main experiment), which also suggests that species dispersal ability clearly affects the way species colonise new patches. While species with sessile adult stages are dependent on larval recruitment from plankton (i.e. which is influenced by species reproductive seasonality), species with motile adult stages appear to be able to arrive and colonise new habitat patches both via larval recruitment from plankton and via dispersal of adult individuals. Although we have not tested the short-term colonisation effect on species response to changes in metacommunity size, this result may suggest that proximity to reef and metacommunity size differently affect the distribution of species according to life-cycle stage; proximity to reef may be relatively more important in determining the ability of larvae colonising experimental patches, whereas metacommunity size may be relatively more important in determining post-settlement dispersal of adults (for motile species). 
0.05) responses (i.e. see response of species richness in the whole assemblage to metacommunity size). We believe that lack of statistical fact that (i) sorting, identifying and enumerating macrofauna is a laborious task and (ii) we adopted a hierarchical framework in which individual

tripled the number of samples. We believe that even though this approach reduced statistical power to detect significant effects, it was also important as it allows one to distinguish scale-dependent effects.

As human populations grow, the natural environment is under increasing pressure leading to the modification and destruction of habitats; such impacts are recognized as one of the greatest threats to biodiversity (Pimm \& Raven 2000). Most common approaches used to predict species loss as a function of the amount of habitat (e.g. Rozenweig 1995) assume implicitly that the mechanisms causing species loss are equivalent among species and their ecological context (Matias et al. 2014). Our results clearly show that species do not all respond in the same way and that part of that variability can be partially explained by the ability and scale at which species disperse (see also Johnson et al. 2001, Munguia \& Miller 2008). Inclusion of traits when modelling responses to habitat loss is a promising avenue to disentangle the contrasting results in the literature (Ewers \& Didham 2006). This study follows a variety of studies calling for the inclusion of further complexity in fieldexperiments (Kareiva 1990), which might come in the form of better knowledge of species functional traits or through testing responses at multiple ecological scales. Unless this is achieved, it will be hard to advance our understanding of the consequences of habitat loss. 


\section{Acknowledgements}

This research was funded by Fundação para a Ciência e Tecnologia (FCT, Portugal) under the project 'METHADE' -

305 PTDC/MAR/120770/2010. It was also partially supported by the European Regional Development Fund through the COMPETE - Operational

306 Competitiveness Programme and national funds through FCT under the project 'PEst-C/MAR/LA0015/2011'. GMM was supported by a post-

307 doctoral grant awarded by FCT (SFRH/BDP/63040/2009). MGM was supported through the Integrated Program of IC\&DT

308 (1/SAESCTN/ALENT-07-0224-FEDER-001755) and a Marie Curie Intra-European Fellowship within the 7th European Community

309 Framework Programme (FORECOMM). The manuscript was substantially improved through the comments of two anonymous reviewers.

\section{LITERATURE CITED}

312 Anderson MJ (2001) A new method for non-parametric multivariate analysis of variance. Austral Ecol 26:32-46.

313 Anderson MJ, Connell SD, Gillanders BM, Diebel CE, Blom WM, Sauders JE, Landers TJ (2005) Relationships between taxonomic resolution 314 and spatial scales of multivariate variation. J Anim Ecol 74:636-646.

315 Cadotte MW (2006) Dispersal and species diversity: a meta-analysis. Am Nat 167:913-924.

316 Cadotte MW, Fukami T (2005) Dispersal, spatial scale, and species diversity in a hierarchical structured experimental landscape. Ecol Lett 8:548-557. 
Chase JM, Burgett AA, Biro E (2010) Habitat isolation moderates the strength of top-down control in experimental pond food webs. Ecology 91:637-643.

320 Chase JM, Ryberg WA (2004) Connectivity, scale-dependence, and the productivity-diversity relationship. Ecol Lett 7:676-683.

321 Ewers RM, Didham RK (2006) Confounding factors in the detection of species responses to habitat fragmentation. Biol Rev 81:117-142.

322 Hanski I (1994) A pratical model of metapopulation dynamics. J Anim Ecol 63:151-162.

323 Hanski I (1999) Metapopulation ecology. Oxford University Press, Oxford.

324 Hanski I, Gilpin ME (1991) Metapopulation dynamics: brief history and conceptual domain. Biol J Linn Soc 42:3-16.

325 Holyoak M (2000) Habitat patch arrangement and metapopulation persistence of predators and prey. Am Nat 156:378-389.

Johnson MP, Allcock AL, Pye SE, Chambers SJ, Fitton DM (2001) The effects of dispersal mode on the spatial distribution patterns of intertidal molluscs. J Anim Ecol 70:641-649.

Kareiva P (1990) Population dynamics in spatially complex environments: theory and data. Philos T Roy Soc B 330:175-190. 148. 
Lecraw RM, Srivastava DS, Romero GQ (2014) Metacommunity size influences aquatic community composition in a natural mesocosm landscape. Oikos 123:903-911.

Leibold MA, Holyoak M, Mouquet N, Amarasekare P, Chase JM, Hoopes MF, Holt RD, Shurin JB, Law R, Tilman D, Loreau M, Gonzalez A

Logue JB, Mouquet N, Peter H, Hillebrand H (2011) Empirical approaches to metacommunities: a review and comparison with theory. Trends Ecol Evol 26:482-491.

MacArthur RH, Wilson EO (1963) An equilibrium theory of insular zoogeography. Evolution 17:373-387.

Martins GM, Faria J, Rubal M, Neto AI (2013) Linkages between rocky reefs and soft-bottom habitats: Effects of predation and granulometry on sandy macrofaunal assemblages. J Sea Res 81:1-9.

Martins GM, Hipólito C, Parreira F, Prestes ACL, Dionísio MA, Azevedo JMN, Neto AI (2016) Differences in the structure and functioning of two communities: Frondose and turf-forming macroalgal dominated habitats. Mar Environ Res 116:71-77.

Matias MG (2013) Macrofaunal responses to structural complexity are mediated by environmental variability and surrounding habitats. Mar Biol 160:493-502.

Matias MG, Gravel D, Münkemüller T, Guilhaumon F, Desjardins-Proulx P, Loreau M, Mouquet N (2014) Estimates of species extinction from species-area relationships strongly depend on ecological context. Ecography 37:431-442. 
Matias MG, Underwood AJ, Coleman RA (2007) Interactions of components of habitats alter composition and variability of assemblages. J Anim Ecol 76:986-994.

Matias MG, Underwood AJ, Coleman RA (2010a) Effects of structural diversity and identity of patches of habitat on diversity of benthic assemblages. Austral Ecol 35:743-751.

Matias MG, Underwood AJ, Hochuli DF, Coleman RA (2010b) Independent effects of patch size and structural complexity on diversity of benthic macroinvertebrates. Ecology 91:1908-1915.

Miller TE, Kneitel JM (2005) Inquiline communities in pitcher plants as a prototypical metacommunity. In: Holyoak M, Leibold MA, Holt RD (eds) Metacommunities: Spatial dynamics and ecological communities. University of Chicago Press, pp. 122-145.

Munguia P (2004) Successional patterns on pen shells communities at local and regional scales. J Anim Ecol 73:64-74.

Munguia P, Miller TE (2008) Habitat destruction and metacommunity size in pen shell communities. J Anim Ecol 77:1175-1182.

Öckinger E, Schweiger O, Crist TO, Debinski DM, Krauss J, Kuussaari M, Petersen JD, Pöyry J, Settele J, Summerville KS, Bommarco R (2010) Life-history traits predict species responses to habitat area and isolation: across-continental synthesis. Ecol Lett 13:969-979.

Pimm SL, Raven P (2000) Biodiversity: Extinction by numbers. Nature 403:843-845.

Shanks AL, Grantham BA, Carr MH (2003) Propagule dispersal distance and the size and spacing of marine reserves. Ecol Appl 13:159-169.

Srivastava DS (1999) Using local-regional richness plots to test for species saturation: pitfalls and potentials. J Anim Ecol 68:1-16.

Virnstein RW, Curran M (1986) Colonization of artificial seagrass versus time and distance from source. Mar Ecol Prog Ser 29:279-288. 
376 Table 1. Summary of PERMANOVA tests comparing responses to size and proximity to reefs in whole assemblages, sessile species or motile species. Responses were calculated at the patch- (i.e. average abundances) or at the metacommunity-scale (i.e. sum of abundances across all 


\begin{tabular}{|c|c|c|c|c|c|}
\hline & & Meta & & & \\
\hline & & Bray-Curtis & Jaccard & Bray-Curtis & Jaccard \\
\hline Size & Whole assemblage & * & $* *$ & * & $* *$ \\
\hline & Sessile assemblage & & & & \\
\hline & Motile assemblage & * & $* *$ & $* *$ & $* *$ \\
\hline Proximity to reef & Whole assemblage & $* * *$ & * & $* * *$ & * \\
\hline & Sessile assemblage & & $* *$ & & $* *$ \\
\hline & Motile assemblage & $* * *$ & & $* * *$ & \\
\hline
\end{tabular}

380 


\section{Figure Captions}

391 Figure 1. Mean (+ SE) numbers of species in metacommunities differing in size and proximity to reefs for (a,b) the assemblage as a whole, $(\mathrm{c}, \mathrm{d})$ the sessile component of the assemblage, and (e,f) the motile component of the assemblage. Analyses were done at two scales: metacommunity- 
404

405

406

407

408

409

410

411

412

413 

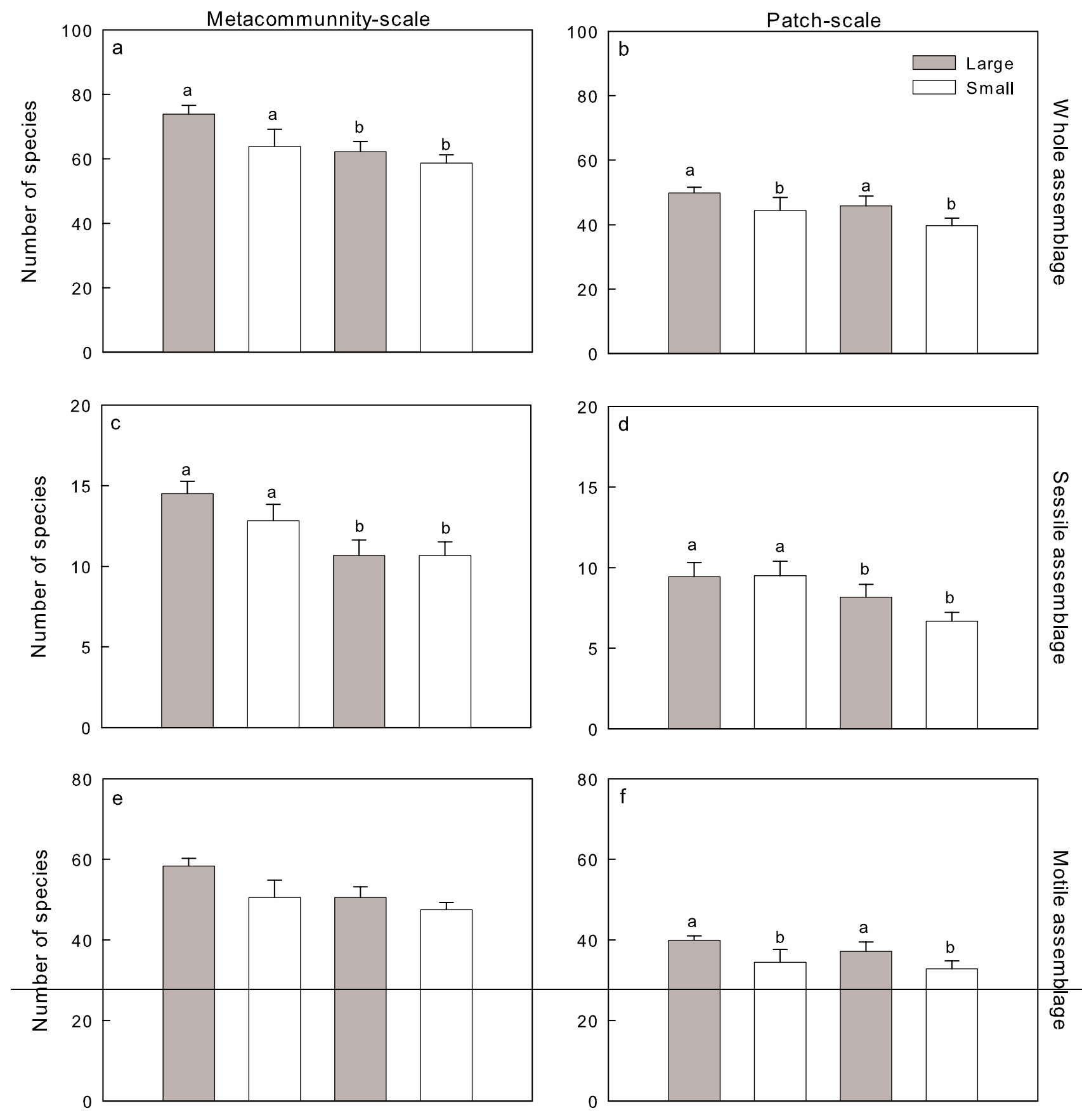


\section{Supplementary online material}

Post-settlement dispersal ability determines structure of marine benthic metacommunities

*Corresponding author: gustavo.om.martins@uac.pt 


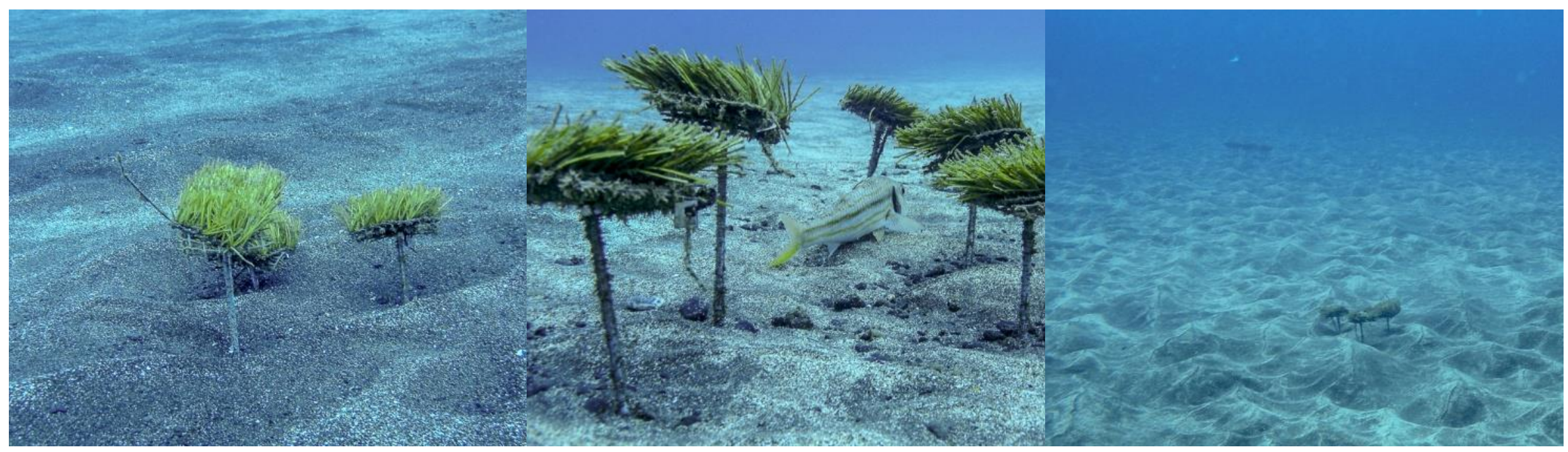

Fig. S1. Photographs of experimental patches and metacommunities (groups of patches) deployed in an inhospitable soft-bottom subtidal habitat. 


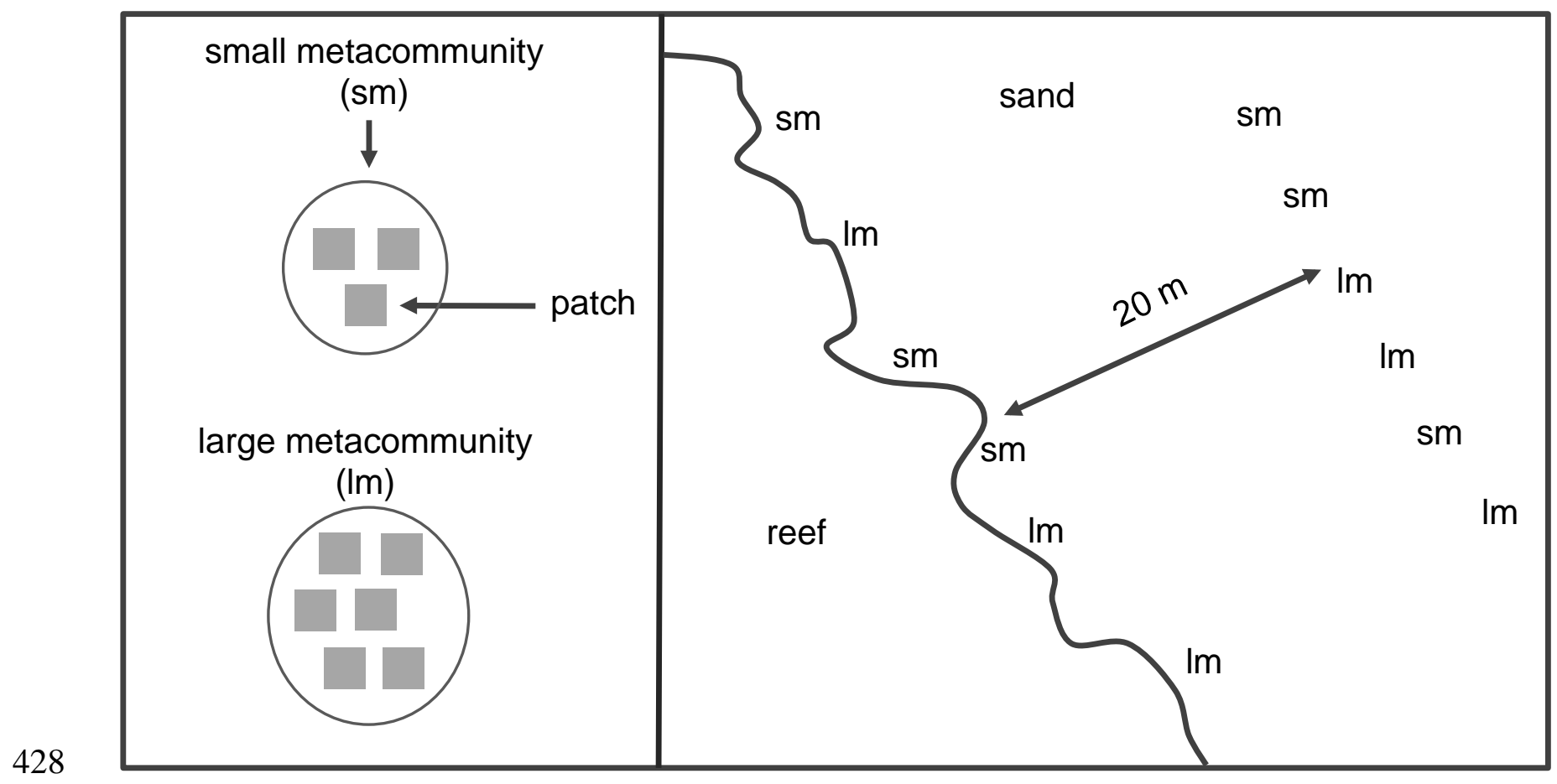

429 Fig. S2. Schematic representation of experimental design. 




430

431

432 Fig. S3. Numbers of species and total abundance in experimental patches after 3, 6 and 18

433 days of deployment and averaged ( \pm SE) over our main experiment (2 months).

434

435

436 
437 Table S1. List of taxa (species or morpho-species) identified present in the experimental 438 turfs.

\begin{tabular}{|c|c|c|c|c|}
\hline Phylum & Class & Subclass/Order & Taxa & $\begin{array}{l}\text { Post-settlement } \\
\text { dispersal }\end{array}$ \\
\hline \multirow[t]{6}{*}{ Annelida } & Clitellata & Oligochaeta & Oligochaeta sp1 & Motile \\
\hline & & & Oligochaeta sp2 & Motile \\
\hline & & & Oligochaeta sp3 & Motile \\
\hline & & & Oligochaeta sp4 & Motile \\
\hline & & & Oligochaeta sp5 & Motile \\
\hline & & & Oligochaeta sp6 & Motile \\
\hline \multirow[t]{19}{*}{ Annelida } & Polychaeta & Errantia & Errantia sp1 & Motile \\
\hline & & & Errantia sp2 & Motile \\
\hline & & & Errantia sp3 & Motile \\
\hline & & & Errantia sp4 & Motile \\
\hline & & & Errantia sp5 & Motile \\
\hline & & & Errantia sp6 & Motile \\
\hline & & & Errantia sp7 & Motile \\
\hline & & & Errantia sp8 & Motile \\
\hline & & & Errantia sp9 & Motile \\
\hline & & & Errantia sp10 & Motile \\
\hline & & & Errantia sp11 & Motile \\
\hline & & & Errantia sp12 & Motile \\
\hline & & & Errantia sp13 & Motile \\
\hline & & & Errantia sp14 & Motile \\
\hline & & & Euphrosine foliosa & Motile \\
\hline & & Sedentaria & Sedentaria sp1 & Sessile \\
\hline & & & Spirorbid sp1 & Sessile \\
\hline & & & Spirorbid sp2 & Sessile \\
\hline & & & Spirorbid sp3 & Sessile \\
\hline
\end{tabular}




\begin{tabular}{|c|c|c|c|c|}
\hline \multirow[t]{3}{*}{ Arthropoda } & Arachnida & Sarcoptiformes & Acarii sp1 & Motile \\
\hline & & & Acarii sp2 & Motile \\
\hline & & & Acarii sp3 & Motile \\
\hline \multirow[t]{27}{*}{ Arthropoda } & Malacostraca & Amphipoda & Abludomelita obtusata & Motile \\
\hline & & & Amphipoda sp1 & Motile \\
\hline & & & Amphipoda sp2 & Motile \\
\hline & & & Amphipoda sp3 & Motile \\
\hline & & & Amphipoda sp4 & Motile \\
\hline & & & Amphipoda sp5 & Motile \\
\hline & & & Amphipoda sp6 & Motile \\
\hline & & & Amphipoda sp7 & Motile \\
\hline & & & Amphitoe rubricata & Motile \\
\hline & & & Aora gracilis & Motile \\
\hline & & & Apherusa jurinei & Motile \\
\hline & & & Caprella acanthifera & Motile \\
\hline & & & Caprella linearis & Motile \\
\hline & & & Dexamine spinosa & Motile \\
\hline & & & Ericthonius difformis & Motile \\
\hline & & & Ericthonius punctatus & Motile \\
\hline & & & Gammarella fucicola & Motile \\
\hline & & & Jassa falcata & Motile \\
\hline & & & Maera grossimana & Motile \\
\hline & & & Phtisica marina & Motile \\
\hline & & & Pseudoprotellaphasma & Motile \\
\hline & & & Thalassosmittiaatlantica & Motile \\
\hline & & Cumacea & Diastylis sp. & Motile \\
\hline & & Decapoda & Decapoda sp1 & Motile \\
\hline & & & Decapoda sp2 & Motile \\
\hline & & & Decapoda sp3 & Motile \\
\hline & & & Decapoda sp4 & Motile \\
\hline
\end{tabular}




\begin{tabular}{|c|c|c|c|c|}
\hline & & & Decapoda sp5 & Motile \\
\hline & & & Decapoda sp6 & Motile \\
\hline & & & Decapoda sp7 & Motile \\
\hline & & & Macropodia sp. & Motile \\
\hline & & & Pagurus sp1 & Motile \\
\hline & & & Pagurus sp2 & Motile \\
\hline & & Isopoda & Anthura gracilis & Motile \\
\hline & & & Dynamene bidentata & Motile \\
\hline & & & Gnathia maxillaris & Motile \\
\hline & & & Janiropsis breviremis & Motile \\
\hline & & Tanaidacea & Leptochelia caldera & Motile \\
\hline & & & Paratanais martinsi & Motile \\
\hline & & & Tanais grimaldii & Motile \\
\hline & Maxillopoda & Copepoda & Copepoda sp1 & Motile \\
\hline & & & Copepoda sp2 & Motile \\
\hline & & & Copepoda sp3 & Motile \\
\hline & & & Copepoda sp4 & Motile \\
\hline & & & Copepoda sp5 & Motile \\
\hline & Pycnogonida & Pantopoda & Achelia echinata & Motile \\
\hline & & & Pycnogonida sp1 & Motile \\
\hline Bryozoa & Stenolaemata & & Bryozoa sp1 & Sessile \\
\hline & & & Bryozoa sp2 & Sessile \\
\hline & & & Bryozoa sp3 & Sessile \\
\hline & & & Bryozoa sp4 & Sessile \\
\hline & & & Bryozoa sp5 & Sessile \\
\hline & & & Bryozoa sp6 & Sessile \\
\hline & & & Bryozoa sp7 & Sessile \\
\hline & & & Bryozoa sp8 & Sessile \\
\hline Chordata & Actinopterygii & Gobiesocidae & Diplecogaster sp1 & Motile \\
\hline & & & Diplecogaster sp2 & Motile \\
\hline
\end{tabular}




\begin{tabular}{|c|c|c|c|c|}
\hline & & & Diplecogaster sp3 & Motile \\
\hline \multirow[t]{7}{*}{ Echinodermata } & Echinoidea & Echinoida & Echinoida sp1 & Motile \\
\hline & & & Echinoida sp2 & Motile \\
\hline & & & Echinoida sp3 & Motile \\
\hline & Ophiuroidea & Ophiurida & Ophiurida sp1 & Motile \\
\hline & & & Ophiurida sp2 & Motile \\
\hline & & & Ophiurida sp3 & Motile \\
\hline & & & Ophiurida sp4 & Motile \\
\hline \multirow[t]{22}{*}{ Mollusca } & Bivalvia & & Bivalve sp1 & Sessile \\
\hline & & & Bivalve sp2 & Sessile \\
\hline & & & Chlamis sp1 & Sessile \\
\hline & & & Chlamis sp2 & Sessile \\
\hline & & & Ervilia castanea & Sessile \\
\hline & & & Limaria hians & Sessile \\
\hline & & & Papillicardium papillosum & Sessile \\
\hline & Gastropoda & & Alvania angioyi & Motile \\
\hline & & & Alvania cancellata & Motile \\
\hline & & & Bittium nanum & Motile \\
\hline & & & Caecum wayae & Motile \\
\hline & & & Gastropoda sp1 & Motile \\
\hline & & & Gastropoda sp2 & Motile \\
\hline & & & Gibbula magus & Motile \\
\hline & & & Jaeropsis brevicornis & Motile \\
\hline & & & Jujubinus pseudogravinae & Motile \\
\hline & & & Lamellaria perspicua & Motile \\
\hline & & & Manzonia unifasciata & Motile \\
\hline & & & Microprotopus maculatus & Motile \\
\hline & & & Nassarius cf cuvierii & Motile \\
\hline & & & Nassarius cf recidivus & Motile \\
\hline & & & Nudibranchia sp1 & Motile \\
\hline
\end{tabular}




\begin{tabular}{|c|c|c|c|c|}
\hline & & & Nudibranchia sp2 & Motile \\
\hline & & & Nudibranchia sp3 & Motile \\
\hline & & & Nudibranchia sp4 & Motile \\
\hline & & & Nudibranchia sp5 & Motile \\
\hline & & & Odostomia cf bernardi & Motile \\
\hline & & & Omalogyra atomus & Motile \\
\hline & & & Philine sp. & Motile \\
\hline & & & Raphitoma sp1 & Motile \\
\hline & & & Raphitoma sp2 & Motile \\
\hline & & & Raphitoma sp3 & Motile \\
\hline & & & Retusa truncatula & Motile \\
\hline & & & Rissoela sp1 & Motile \\
\hline & & & Setia subvaricosa & Motile \\
\hline & & & Solariella azorensis & Motile \\
\hline & & & Tricolia pullus azorica & Motile \\
\hline & & & Tricolia $\mathrm{sp} 1$ & Motile \\
\hline & & & Trophonopsis muricatus & Motile \\
\hline Platyhelminthes & Rhabditophora & Tricladida & Planaria sp1 & Motile \\
\hline Porifera & & & Grantia sp. & Sessile \\
\hline & & & Porifera sp1 & Sessile \\
\hline & & & Porifera sp2 & Sessile \\
\hline Retaria & & & Foraminifera sp1 & Motile \\
\hline & & & Foraminifera sp2 & Motile \\
\hline & & & Foraminifera sp3 & Motile \\
\hline Sipuncula & Sipunculidea & Sipunculiformes & Sipuncula sp1 & Motile \\
\hline & & & Sipuncula sp2 & Motile \\
\hline & & & Sipuncula sp3 & Motile \\
\hline & & & Sipuncula sp4 & Motile \\
\hline & & & Sipuncula sp5 & Motile \\
\hline & & & Sipuncula sp6 & Motile \\
\hline
\end{tabular}


442 PERMANOVA based on Euclidean distances.

\begin{tabular}{|c|c|c|c|c|c|c|c|c|c|c|c|c|c|}
\hline \multirow[b]{3}{*}{ Source } & \multirow[b]{3}{*}{$\mathrm{df}$} & \multicolumn{6}{|c|}{ Patch-scale } & \multicolumn{6}{|c|}{ Metacommunity-scale } \\
\hline & & \multicolumn{2}{|c|}{ (a) Whole } & \multicolumn{2}{|c|}{ (b) Sessile } & \multicolumn{2}{|c|}{ (c) Motile } & \multicolumn{2}{|c|}{ (a) Whole } & \multicolumn{2}{|c|}{ (b) Sessile } & \multicolumn{2}{|c|}{ (c) Motile } \\
\hline & & $F$ & $\mathrm{P}$ & $F$ & $\mathrm{P}$ & $F$ & $\mathrm{P}$ & $F$ & $\mathrm{P}$ & $F$ & $\mathrm{P}$ & $F$ & $\mathrm{P}$ \\
\hline Location $=\mathrm{L}$ & 1 & $<0.01$ & 0.965 & 6.94 & 0.020 & 0.54 & 0.504 & $<0.01$ & 0.957 & 2.35 & 0.137 & 0.29 & 0.598 \\
\hline $\begin{array}{l}\text { Proximity to reef } \\
=\mathrm{P}\end{array}$ & 1 & 2.08 & 0.183 & 8.73 & 0.006 & 0.91 & 0.328 & 5.06 & 0.036 & 11.88 & 0.003 & 3.42 & 0.081 \\
\hline Size $=S$ & 1 & 3.77 & 0.064 & 1.08 & 0.328 & 4.59 & 0.048 & 3.26 & 0.09 & 0.92 & 0.334 & 3.42 & 0.084 \\
\hline $\mathrm{L} \times \mathrm{P}$ & 1 & Pooled & & Pooled & & Pooled & & Pooled & & Pooled & & Pooled & \\
\hline $\mathrm{L} \times \mathrm{S}$ & 1 & Pooled & & Pooled & & Pooled & & Pooled & & Pooled & & Pooled & \\
\hline $\mathrm{P} \times \mathrm{S}$ & 1 & 0.01 & 0.915 & 1.25 & 0.28 & 0.06 & 0.787 & 0.75 & 0.394 & 0.92 & 0.366 & 0.68 & 0.415 \\
\hline $\mathrm{L} \times \mathrm{P} \times \mathrm{S}$ & 1 & Pooled & & Pooled & & Pooled & & Pooled & & Pooled & & Pooled & \\
\hline Res & 16 & & & & & & & & & & & & \\
\hline
\end{tabular}

443 Pooling was done when P > 0.25 (Underwood 1997). 
449 Table S3. Permutational ANOVA testing the response of assemblage structure to size and proximity to reef (as in Table C1). Analyses were

450 performed using PERMANOVA based on Bray-Curtis and Jaccard similarities.

\begin{tabular}{|c|c|c|c|c|c|c|c|c|c|c|c|c|c|}
\hline \multirow[b]{4}{*}{ Source } & & \multicolumn{6}{|c|}{ Patch-scale } & \multicolumn{6}{|c|}{ Metacommunity-scale } \\
\hline & & \multicolumn{3}{|c|}{ Bray -Curtis } & \multicolumn{3}{|c|}{ Jaccard } & \multicolumn{3}{|c|}{ Bray-Curtis } & \multicolumn{3}{|c|}{ Jaccard } \\
\hline & & Whole & Sessile & Motile & Whole & Sessile & Motile & Whole & Sessile & Motile & Whole & Sessile & Motile \\
\hline & df & $F$ & $F$ & $F$ & $F$ & $F$ & $F$ & $F$ & $F$ & $F$ & $F$ & $F$ & $F$ \\
\hline Location $=\mathrm{L}$ & 1 & $14.07 * * *$ & $5.39 * * *$ & $16.40 * * *$ & $3.61 * * *$ & $5.70 * * *$ & $3.24 * * *$ & $14.07 * * *$ & $5.39 * * *$ & $16.40 * * *$ & $3.61 * * *$ & $5.75 * * *$ & $3.24 * * *$ \\
\hline Proximity to & 1 & 2.52 & 1.18 & 2.23 & 2.00 & 1.25 & 2.21 & 2.53 & 1.19 & 2.23 & 2.00 & 1.25 & 2.21 \\
\hline \multicolumn{14}{|l|}{ reef $=\mathrm{P}$} \\
\hline Size $=S$ & 1 & $2.08 *$ & 0.96 & $2.56^{* *}$ & $2.07 * *$ & 0.91 & $2.30 * *$ & $2.08 *$ & 0.96 & $2.56^{*}$ & $2.07 * *$ & 1.21 & $2.30 * *$ \\
\hline $\mathrm{L} \times \mathrm{P}$ & 1 & $5.59 * * *$ & 1.89 & $8.22 * * *$ & $1.74 *$ & $3.62 * *$ & 1.50 & $5.59 * * *$ & 1.89 & $8.22 * * *$ & $1.74 *$ & $3.65^{* *}$ & 1.50 \\
\hline $\mathrm{LxS}$ & 1 & Pooled & 1.42 & Pooled & Pooled & 1.31 & Pooled & Pooled & 1.42 & Pooled & Pooled & Pooled & Pooled \\
\hline PX S & 1 & 0.27 & 0.17 & 0.37 & 0.87 & 0.29 & 0.98 & 0.27 & 0.17 & 0.37 & 0.87 & 0.20 & 0.98 \\
\hline LX P X S & 1 & 1.52 & Pooled & 1.64 & 1.55 & Pooled & 1.61 & 1.52 & Pooled & 1.64 & 1.55 & 1.48 & 1.61 \\
\hline
\end{tabular}

451 Pooling was done when $\mathrm{P}>0.25$ (Underwood 1997). 
Table S4. SIMPER analysis comparing (a) occurrences (presence-absences) of sessile taxa in habitats differing in proximity to reefs (close and

454 away), and (b) abundances (untransformed) of motile taxa in habitats differing in proximity to reef and size (large and small metacommunities).

\begin{tabular}{|c|c|c|c|c|c|c|c|c|}
\hline \multirow[b]{2}{*}{ Taxa } & \multicolumn{4}{|c|}{ Proximity to reef effect } & & & & \\
\hline & Av. away & Av. close & Av. Diss. & $\%$ Cont. & & & & \\
\hline \multicolumn{9}{|c|}{ (a) Sessile aassemblages } \\
\hline Sessile polychaetes & 0.50 & 0.58 & 4.96 & 39 & & & & \\
\hline Porifera & 0.75 & 0.83 & 3.69 & 29 & & & & \\
\hline Cnidarians & 0.92 & 0.92 & 1.95 & 15 & & & & \\
\hline Bryozoans & 0.92 & 1.00 & 1.16 & 9 & & & & \\
\hline (b) Motile assemblage & \multicolumn{4}{|c|}{ Proximity to reef effect } & \multicolumn{4}{|c|}{ Size effect } \\
\hline Taxa & Av. away & Av. close & Av. Diss. & $\%$ Cont. & Av. Large & Av. Small & Av. Diss. & $\%$ Cont. \\
\hline Amphipods & 2486.9 & 658.1 & 44.48 & 80 & 1668.7 & 1474.8 & 36.11 & 76 \\
\hline Motile polychaetes & 75.0 & 120.1 & 2.15 & 4 & 103.6 & 91.5 & 2.15 & 5 \\
\hline Gastropods & 113.8 & 79.6 & 1.65 & 3 & 104.4 & 89.0 & 1.76 & 4 \\
\hline Oligochaetes & 59.6 & 26.8 & 1.09 & 2 & 53.8 & 32.6 & 1.03 & 2 \\
\hline Cumaceans & 56.3 & 24.9 & 0.96 & 2 & 42.4 & 38.9 & 0.97 & 2 \\
\hline Pycnogonids & - & - & & & 42.9 & 29.3 & 0.98 & 2 \\
\hline
\end{tabular}



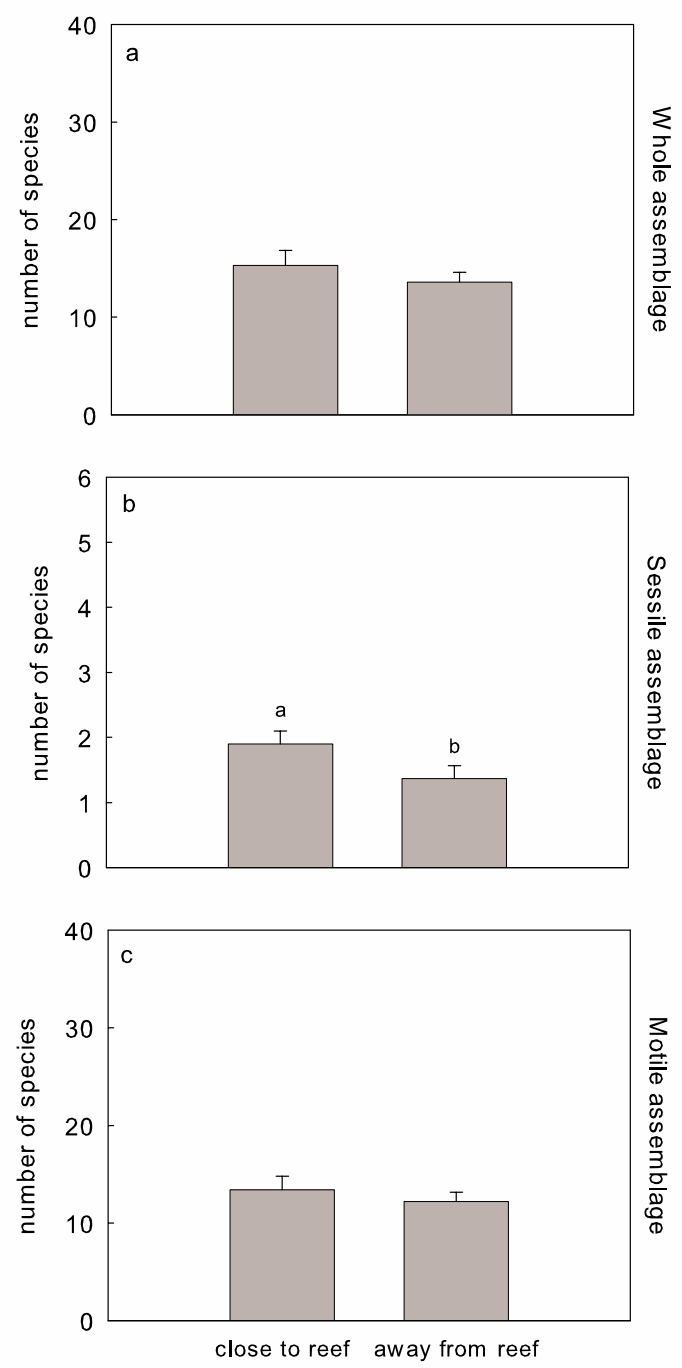

457 Figure S4. Mean (+SE) numbers of species found on experimental patches deployed close 458 and away from the reef after 3 days of colonisation. Data are (a) the total numbers of species 459 (b), numbers of sessile species only, and (c) numbers of motile species only. Note that this 460 experiment was repeated $\mathrm{X}$ times and that there were no differences between trials. Letters 461 indicate significant pairwise comparisons of means at $\mathrm{P}<0.05$. 
465 Table S5. Permutational ANOVA comparing the short-term response of species richness to

466 proximity to reef (close and away) when considering the (a) whole assemblage, (b) the sessile

467 assemblage and (c) the motile assemblage. Analyses were performed using PERMANOVA

468 based on Euclidean distances.
(a) Whole
(b) Sessile
(c) Motile

\begin{tabular}{lccccccc} 
Source & df & $F$ & $\mathrm{P}$ & $F$ & $\mathrm{P}$ & $F$ & $\mathrm{P}$ \\
\hline Location $=\mathrm{L}$ & 1 & 7.71 & 0.186 & 9.14 & 0.185 & 7.42 & 0.168 \\
Time = T & 2 & 2.23 & 0.475 & 2.59 & 0.348 & 2.15 & 0.415 \\
Proximity to & 1 & 0.93 & 0.377 & 4.30 & 0.039 & 0.84 & 0.396 \\
reef = P & & & & & & & \\
$\mathrm{L} \times \mathrm{T}$ & 2 & 3.35 & 0.044 & 1.06 & 0.335 & 3.14 & 0.060 \\
$\mathrm{~L} \times \mathrm{P}$ & 1 & Pooled & & Pooled & & Pooled & \\
$\mathrm{T} \times \mathrm{P}$ & 2 & 1.63 & 0.200 & Pooled & & Pooled & \\
$\mathrm{L} \times \mathrm{T} \times \mathrm{P}$ & 2 & Pooled & & Pooled & & Pooled & \\
$\mathrm{R}$ & & & & &
\end{tabular}


Table S6. PERMANOVA comparing the short-term response of assemblages to proximity to reef (close and away) when considering the (a)

471 whole assemblage, (b) the sessile assemblage and (c) the motile assemblage. Analyses were two different dissimilarity measures: Bray-Curtis

472 and Jaccard index.

\begin{tabular}{|c|c|c|c|c|c|c|c|c|c|c|c|c|c|}
\hline \multirow[b]{3}{*}{ Source } & \multirow[b]{3}{*}{$\mathrm{df}$} & \multicolumn{6}{|c|}{ Bray-Curtis } & \multicolumn{6}{|c|}{ Jaccard } \\
\hline & & \multicolumn{2}{|c|}{ (a) Whole } & \multicolumn{2}{|c|}{ (b) Sessile } & \multicolumn{2}{|c|}{ (c) Motile } & \multicolumn{2}{|c|}{ (a) Whole } & \multicolumn{2}{|c|}{ (b) Sessile } & \multicolumn{2}{|c|}{ (c) Motile } \\
\hline & & $F$ & $\mathrm{P}$ & $F$ & $\mathrm{P}$ & $F$ & $\mathrm{P}$ & $F$ & $\mathrm{P}$ & $F$ & $\mathrm{P}$ & $F$ & $\mathrm{P}$ \\
\hline Location $=\mathrm{L}$ & 1 & 7.71 & 0.186 & 1.04 & 0.338 & 3.72 & 0.178 & 2.40 & 0.182 & 3.16 & 0.104 & 2.28 & 0.171 \\
\hline Time $=\mathrm{T}$ & 2 & 2.23 & 0.475 & 0.44 & 0.851 & 2.20 & 0.171 & 1.12 & 0.391 & 0.88 & 0.486 & 1.13 & 0.397 \\
\hline Proximity to & 1 & 0.93 & 0.377 & 4.09 & 0.003 & 2.04 & 0.167 & 1.46 & 0.083 & 2.48 & 0.046 & 1.41 & 0.11 \\
\hline \multicolumn{14}{|l|}{ reef $=\mathrm{P}$} \\
\hline $\mathrm{L} \times \mathrm{T}$ & 2 & 3.35 & 0.044 & 2.97 & 0.011 & 3.17 & 0.001 & 2.36 & 0.001 & 1.61 & 0.104 & 2.44 & 0.001 \\
\hline $\mathrm{L} \times \mathrm{P}$ & 1 & Pooled & & Pooled & & Pooled & & Pooled & & Pooled & & Pooled & \\
\hline $\mathrm{T} \times \mathrm{P}$ & 2 & 1.63 & 0.200 & Pooled & & Pooled & & Pooled & & Pooled & & Pooled & \\
\hline $\mathrm{L} \times \mathrm{T} \times \mathrm{P}$ & 2 & Pooled & & Pooled & & 1.34 & 0.139 & Pooled & & Pooled & & Pooled & \\
\hline Res & 48 & & & & & & & & & & & & \\
\hline
\end{tabular}


473 Table S7. SIMPER analysis comparing patterns of occurrence (presence-absence data) of 474 sessile taxa in habitats differing in proximity to reefs (close and away).

\begin{tabular}{lcccc}
\hline Taxa & Av. Away & Av. Close & Av. Diss. & \% Cont. \\
\hline Ervilia castanea & 0.73 & 0.87 & 17.58 & 31 \\
Unidentified bryozoan sp1 & 0.13 & 0.37 & 10.62 & 19 \\
Gregariella semigranata & 0.17 & 0.13 & 8.01 & 14 \\
Papillicardium papillosum & 0.10 & 0.20 & 6.91 & 12 \\
Unidentified bryozoan sp2 & 0.10 & 0.03 & 2.93 & 5 \\
Limaria hians & 0.03 & 0.03 & 2.43 & 4 \\
Porifera & 0.07 & 0.00 & 2.04 & 4 \\
Unidentified bryozoan sp3 & 0.00 & 0.07 & 1.46 & 3 \\
\hline
\end{tabular}

475

476

477

478

479 
